\title{
Precarização e individualização: em que sociedade vivemos? Reflexões sobre a validade empírica do "discurso sobre a segunda modernidade"*
}

\author{
Werner Thole, \\ Sarina Ahmed, \\ Davina Höblich**
}

\section{Motivo e oportunidade}

"San Precario", o novo santo dos italianos, não se parece com um protegido; ele usa calças tipo bombachinha, no estilo do século 16, e uma camisa pólo parecida com a de jogador de futebol. Seus devotos são vendedo-

* Texto em homenagem a Friedrich Ortmann, pelo $65^{\circ}$ aniversário. Texto original em alemão, traduzido por Emil A. Sobottka.

** Werner Thole é doutor e livre-docente em Serviço Social com ênfase em pedagogia social, professor no Instituto de Pedagogia Social e Sociologia das Etapas da Vida (Lebensalter) da Universidade de Kassel, onde pesquisa sobre questões relativas a teoria, profissão e práxis da Pedagogia Social, em especial no trabalho com crianças, adolescentes e jovens. Sarina Ahmed é pedagoga e assistente no mesmo instituto, onde pesquisa em especial sobre jovens e sua cultura. Davina Höblich também é pedagoga e colaboradora do mesmo instituto, onde pesquisa sobre socialização, gênero e juventude, assim como a prática do Serviço Social com crianças e jovens. Endereço: wthole@uni-kassel.de.

\begin{tabular}{l|l|l|l|l|l|} 
Civitas & Porto Alegre & v. 7 & n. 2 & jul.-dez. 2007 & p. 129-151 \\
\hline
\end{tabular}


res, estagiários, assim como trabalhadores de serviços de entrega, de call centers e de mercados varejistas. "San Precario" é seu anjo, o "protetor dos desprotegidos", dos "pseudo-autônomos" e de "todos trabalhadores cujo contrato de trabalho está por um fio", ou seja, daqueles que têm uma ocupação em condição precária e desprotegida e que aos poucos começam a se organizar. Mais de $40 \%$ dos novos contratos de trabalho na Itália entrementes são temporários (Namuth, 2006, p. 34). A sorrateira precarização e o aprofundamento das tendências de divisão da sociedade, observável também em outros estados, parece desmistificar as constatações disponíveis sobre uma profunda transformação social. Fundamentam esta constatação indícios de uma indiferenciação radical das estruturas sociais, uma diluição das biografias normais, ou seja, da construção pessoal de trajetórias ao longo da vida, assim como de implosão das redes e dos vínculos sociais, da democracia nos estados nacionais e uma ressignificação das formas de produção e da relevância do conhecimento.

Independentemente das diferentes codificações teóricas do desenvolvimento social, a atualidade e visibilidade das formas de exclusão social são indiscutíveis. "Devido ao desemprego estrutural, elevado risco de empobrecimento e diminuição dos benefícios sociais estatais está acontecendo uma polarização entre grupos privilegiados e desprivilegiados” (Bude e Lantermann, 2006, p. 1), e é cada vez mais difícil ignorar situações problemáticas que se manifestam como desemprego, pobreza, falta de moradia e marginalização social e cultural (Bieling, 2000, p. 179; Anhorn e Bettinger, 2005). O aprofundamento das desigualdades sociais e a ampliação de novos mecanismos de exclusão e apartamento social (Mackert, 2004) parecem ser tão impossíveis de serem captados em sua complexidade pela tese da individualização derivada da teoria da modernização quanto pela suposição de que as dinâmicas estruturais do desenvolvimento atual só alteram marginalmente o caráter da sociedade, sem refundar suas estruturas. Perguntas sobre o perfil da mobilidade social, suas causas, processos e fatores determinantes assim como sobre o impacto e a persistência de recursos adscritos desde a origem sobre a ocupação de uma posição na sociedade e, por conseguinte, sobre uma trajetória de vida bem-sucedida e sobre a participação nos recursos sociais sem dúvida tornam-se atuais. 
Processos de exclusão e de estabilização de desigualdades são fomentados por decisões políticas neoliberais e por lógicas do agir econômico que se sentem comprometidas exclusivamente com a racionalidade da acumulação de capital. Visto em seu todo, o caráter de classe das sociedades ocidentais modernas de modo algum é suavizado; ao contrário, ele é adensado (Vester et al., 2001; Herkommer, 2005; Deppe, 2005; Bourdieu, 1997). Segundo esta percepção da realidade, o Serviço Social deve concentrar-se, novamente, sobretudo no apoio aos "supérfluos”, “desviantes” e "invisíveis” da sociedade.

Este texto pretende seguir estes pressupostos iniciais e questionar criticamente a tese de uma transformação fundamental, radical e complexa da sociedade, mediante o recurso a novos estudos. Informações empíricas referentes à reprodução da mobilidade, heterogeneidade e continuidade sociais são analisadas, em diversos níveis e com referência ao estabelecimento de desigualdades sociais, para verificar se e, caso sejam, em que medida elas se harmonizam com os diagnósticos sobre individualização e flexibilização da sociedade, por um lado, ou a agudização de desigualdades baseadas em estruturas de classe, por outro.

\section{Reflexões sobre a indiferenciação da estrutura social e a sedimentação de desigualdades sociais}

\section{A estrutura de sociedades modernas - hipóteses teóricas fundamentais}

Ao que tudo indica, a pergunta sobre como as atuais mudanças radicais nas estruturas sociais podem ser captadas teoricamente e como localizar os diversos mecanismos, dinâmicas e formas da desigualdade social não pode ser respondida univocamente. Ao contrário, dissenso parece reinar também no diagnóstico sociológico contemporâneo. Consenso parece haver unicamente na percepção de que os modelos teóricos clássicos, que constroem tipologias hierárquicas da sociedade, modelos que partem da teoria do duplo caráter da mercadoria para diagnosticar uma estruturação da sociedade em classes (Marx, 1974), por si sós não são mais confiáveis. ${ }^{1}$ No mínimo, nas

1 Enquanto as teorias de classe, com sua fixação na estrutura da desigualdade social, bem como numa correspondente consciência de classe como orientação coletiva de grupo "lacram 
discussões relevantes das Ciências Sociais dificilmente se espera delas, em sua versão clássica, ainda uma capacidade explicativa - não apenas porque a estrutura social fundamental comunicada através deles seja empiricamente incerta, e porque o modelo de uma "classe em si" na prática dificilmente ainda articula uma "classe para si" através de engajamento político, mas também porque não se consegue constatar uma esfera econômica como uma dimensão que fosse capaz de determinar e dirigir unilateralmente a sociedade. Pelo menos desde que Ulrich Beck (1986, p. 121) sugeriu o fim da sociedade de classe, os outrora destacados diagnósticos sociais com enfoque em classes e estratificação social perderam credibilidade e se revelaram analiticamente frágeis por sua dramatização da dimensão vertical da desigualdade social (Bieling, 2000, p. 15). ${ }^{2}$

Teorias sociais recentes de inspiração marxista acolhem, ora mais ora menos explicitamente, reflexões a este respeito e tentam não mais explicar a desigualdade social exclusivamente a partir de formações econômicas; elas levam em consideração fatores econômicos, políticos e sociais, e, ao lado de uma reestruturação global do capitalismo, da gestão da produção através de tecnologias da informação, da diminuição dos custos com salários e da desregulamentação do mercado de trabalho, também diagnosticam uma diferenciação do consumo, a reestruturação ou desmonte do estado de bem-estar social no sentido de priorizar a auto-ajuda, o enfraquecimento dos sindicatos e a volta do darwinismo social. Elas se valem tanto de argumentos estruturais como da teoria da ação e, ao levar em consideração as instituições e as organizações, vão além da contraposição entre indivíduos e sociedade (Hradil,

artificialmente” a realidade, as teorias da estratificação social com freqüência amalgamam grupos heterogêneos de pessoas e assim fragmentam grupos homogêneos reais através de delimitações artificiais de estratos enfocando determinadas características. Tanto as teorias que enfocam a classe como as que enfocam a estratificação revelam seus limites para captar tanto teórica como empiricamente o fenômeno das "camadas sociais médias".

2 Diagnósticos sobre o "fim da sociedade do trabalho" (Dahrendorf, 1983; Gorz, 1980) colocam em dúvida as análises da desigualdade social que se referem exclusivamente à posição das pessoas no mercado de trabalho. Também as descrições sobre uma flexibilização geral do mercado de trabalho necessitam uma análise mais acurada. Há estudos que mostram que esta se revela, sobretudo, como uma mobilidade interna às empresas e que ela é menor nas grandes indústrias que nas pequenas - a estabilidade das relações empregatícias cresce com o tamanho da empresa - e que o que mais se espera dos empregados não é uma flexibilidade na ocupação mas sim na carga horária do trabalho (Keller e Seifert, 2006, p. 245; Erlinghagen e Knuth, 2003). 
2005). As reflexões de Pierre Bourdieu pertencem a esta tendência. Ele atribui à teoria marxista das classes a "incapacidade de fazer justiça às diferenças objetivamente constatáveis em sua totalidade", porque "ela restringe o mundo social ao campo econômico" e com isso "forçosamente só consegue determinar a posição social com base no lugar ocupado nas relações econômicas de produção" (Bourdieu, 1985, p. 31) e, por conseguinte, eclipsa os aspectos culturais. Bourdieu (1985, p. 33; Bourdieu, 1983) parte do suposto que os campos que constituem o espaço social "em maior ou menor medida, em seu modo de funcionamento e na trajetória de seu desenvolvimento correspondem a campos subalternos ao campo de produção econômica”, mas devido a sua autonomia relativa constituem um espaço multidimensional (Bourdieu, 1985, p. 31). ${ }^{3}$

De acordo com estas visões, a estreita vinculação entre propriedade dos meios de produção, condições e modos de vida, consciência coletiva e interesses políticos de determinados grupos da população na forma de classes (Herkommer, 1983; 2005) perdeu muito de seu poder explicativo face à erosão das interpretações específicas de classe, à pluralização dos modos e estilos de vida, assim como ao fato que desigualdades sociais em sociedades modernas, complexas, não são determinadas unicamente pela posição ocupada nas relações de produção. Mesmo quando subsistem dúvidas com relação às manifestações e contornos concretos das mudanças na estrutura social entre a estratificação da sociedade manifesta estruturalmente e a identificação da formação de classes sociais feita com base em enquadramentos subjetivos, feita através de visões de mundo, das condições de vida e de interesses aí sedimentados, abre-se uma inequívoca discrepância - a diversificação e despadronização sócio-estrutural dos grupos sociais e a permeabilização pelo menos parcial das situações de classe dificilmente ainda são contestadas

3 Também Reinhard Kreckel $(1983,1992)$ quer ultrapassar as limitações da análise fixada em classes, valendo-se de uma teoria política da desigualdade social, que concebe as estruturas sociais como círculos concêntricos de influência do estado, do mercado de trabalho e do capital, assim como das associações, dos novos movimentos sociais e, finalmente, da população socialmente estruturada. Ele advoga por um modelo de raciocínio em termos de centro e periferia. As forças sociais abstratas que são relevantes para a desigualdade e suas associações institucionais e organizacionais em seu conjunto, através da figura de um centro e uma periferia, formam essencialmente as estruturas da desigualdade social, de tal modo que "de constelações de poder ambivalentes e intensas [...] surjam conjuntos de interesses múltiplos e ambivalentes, e não linhas inequívocas de conflito" (Kreckel, 1983, p. 10). 
(Vester et al., 1993; 2001; Bieling, 2000, p. 23). "As diferenças econômicas de classe não são mais as únicas diferenças sociais que determinam o funcionamento da sociedade, a atuação de atores históricos ou a capacidade imaginativa da cultura cotidiana. Antes, o mundo da vida como contexto de ação é marcado por uma 'complexa mescla' de desigualdades específicas da classe, do grupo e de manifestações atomizadas da desigualdade” (Berger e Vester, 1998, p. 14; Bourdieu, 1997; Kreckel, 1998).”4 Na pesquisa sobre desigualdade, Peter A. Berger e Michael Vester distinguem os modelos de classes e camadas centrados no trabalho como paradigma da homogeneidade em oposição ao paradigma da diferenciação, que acolhe novas dimensões que vão além da centralidade do trabalho e dirige seu olhar para "tendências do 'desacoplamento' entre os momentos objetivo e subjetivo da estrutura social, entre condições sociais, grupos e estilos de vida” (Berger e Vester, 1998, p. 11). No entanto, segundo eles, fronteiras sociais tradicionais estariam sendo fortalecidas e processos de exclusão se constituindo duradouramente, com o que a diferenciação das condições de vida não apenas seguiria premissas culturais, mas ainda, sobretudo, premissas específicas da camada social (Vester et al., 1993).

Em oposição aos diagnósticos assim fundamentados crescem em importância reflexões que partem da constatação de uma multiplicação e diferenciação da estrutura social atual da Alemanha e das constituições, estilos e formas perceptíveis e elegidas de vida, de grupos e orientações que liberam radicalmente o indivíduo das relações de classe e dos vínculos normativos (Beck, 1986, p. 206). Coerentemente, estas análises se distanciam da localização da desigualdade social através de categorias vinculadas a grandes grupos como classe e camada social. No rastro da transformação da sociedade industrial em sociedade de risco e do "efeito elevador" com ele relacionado, que elevaria o nível geral de vida - segundo argumenta U. Beck, como importante representante destas concepções teóricas sobre modernização (1986, p. 122) -, as questões de classe como questões relativas à desigualdade social

4 Estas indicações de modo algum são novas. Max Weber, meio século após Karl Marx critica que os fenômenos articulados no conceito de classe nem sempre ocorrem juntos na realidade. Mas a tipologia de Max Weber para classes (situação semelhante na economia e no trabalho), estamentos (prestígio e modos de vida comuns) e partidos (grupos de interesse político), embora forneça descrições bastante detalhadas da estrutura da desigualdade social, tem uma capacidade explicativa muito limitada para identificação das causas desta desigualdade (Kreckel, 1983; Hradil, 2005, p. 60). 
perderam sua importância. Desemprego e outras situações problemáticas teriam se generalizado e, portanto, normalizado, "como destino individual específico de fases da vida, não são mais um destino de classe ou de grupo marginalizado" (Beck, 1986, p. 148), mas ameaçam todos indivíduos igualmente. De um lado, desemprego, subocupação, exclusão social e formas particulares de insegurança econômica afetam também as "classes médias". Por outro lado, entre aqueles que possuem uma ocupação qualificada, capaz de dar segurança material e sentido, e aqueles que não têm trabalho abre-se um novo e profundo fosso (Beck, 1986, p. 84).

Segundo certas análises, também e talvez até principalmente devido a esta, ocorre uma desdiferenciação da estrutura social, mediante a qual desigualdades sociais, embora possam se adensar ainda em torno de dimensões "clássicas”, não são percebidas em sua especificidade social enquanto estruturação devido aos novos horizontes de experiência no mundo da vida e aos modelos de interpretação individualizados; são, ao contrário, interpretadas pelos indivíduos como consequiência de seu próprio agir (Bieling, 2000, p. 106). A tese da desvinculação dos problemas sociais, que U. Beck sintetizou na expressão: “A miséria é hierárquica, a poluição é democrática” (Beck, 1986, p. 48) é atualmente acolhida em uma série de pesquisas e secundada, por exemplo, através da figura da desvinculação espacial e social de situações de problema e risco (Berger, 1996; Leibfried et al., 1995); segundo esta codificação teórica, a estruturação das desigualdades sociais pode ser identificada através de características horizontais.

\section{Sobre as evidências empíricas de uma mudança social estrutural: considerações e constatações a partir de análises secundárias}

A questão central que permanece é se e em que medida a composição estrutural das sociedades modernas, e aqui especialmente a da República Federal da Alemanha, se deslocou efetivamente de um perfil de segmentação vertical e bastante fechada para uma segmentação horizontal e de curta duração, graças ao aumento da mobilidade em relação a preferências culturalestéticas e variações dos estilos de vida, às possibilidades de participação nas ofertas relativas a formação, nos recursos culturais e sociais, assim como devido à sucessiva erosão das consistências de status e à desestruturação de situações de vida - no sentido de diluição da rigidez das estruturas determi- 
nantes da vida de classes, grupos ou camadas sociais. Com base em pesquisas mais recentes, no que segue será buscado verificar esta questão à luz de relações documentadas entre estilos de vida, classes, situações de vida, hábitos de lazer, sucesso na formação e trajetória profissional; também serão analisados os diagnósticos e as teses contraditórias sobre a individualização da sociedade como um todo versus a reprodução da sociedade e das desigualdades sociais de modo estruturalmente consistente e com especificidade de classe.

Petra Stein, numa pesquisa atual, analisa a relação entre mobilidade e estilos de vida e, com base no conceito de habitus de P. Bourdieu, pergunta "se o estilo de vida alcançado dentro de um contexto social permanece invariável ao longo da trajetória de vida e face a alterações nos recursos, e como as pessoas adaptam seu estilo de vida aos recursos presentemente disponíveis” (Stein, 2005, p. 204). A dimensão estilo de vida é operacionalizada através dos indicadores da Pesquisa Geral da População em Ciências Sociais (Allbus, 1998) e condensado em três tipos: alta cultura, trivial e tenso (Schulze, 1992). Nesta pesquisa de análise secundária, a origem social é determinada unicamente através de uma distribuição dos grupos profissionais em classes sociais e sua localização na escala social, tomando como base a posição profissional do pai. Os resultados indicam tanto uma "estabilidade dos modelos de estruturação relevantes para o estilo de vida como esforços de adaptação dos atores a mudanças na disponibilidade de recursos” (Stein, 2005, p. 206). Com isto se ratifica em termos gerais a tese da herança intergeracional de estilos de vida através de modelos de percepção, pensamento e ação relativos a estética, gosto e estilo típicos de grupo e veiculados pela influência da família nas crianças, muito embora se constate uma inclinação para o tipo alta cultura influenciada mais pela posição atual do que pela origem social. "As pessoas se orientam mais pelas regras do status no qual ingressaram do que por sua classe social de origem” (Stein, 2005, p. 225; Bourdieu, 1982). De um modo geral, a capacidade das classes sociais de influenciarem seus membros mesmo para além do tempo de sua pertinência e de socializarem novos membros parece distinta de uma para outra. Interessante constatar que são justamente os grupos com os volumes maiores e menores de recursos culturais e econômicos que têm maior capacidade de influência. As camadas médias revelam uma capacidade muito menor de influência, tanto na força marcante através da socialização primária como na socialização de novos membros. Assim, por exemplo, pessoas que saíram das classes superiores e das inferiores em 
direção às médias mantêm um maior apego a ou desprezo pela alta cultura do que pessoas das camadas médias quando têm mobilidade social ascendente ou descendente. Com relação ao apego a ou ao desprezo pelos esquemas da alta cultura pode-se falar de uma persistência ou de uma divisão da sociedade, fundamentada na socialização primária, pelo menos relativa às classes inferiores e superiores. P. Stein (2005, p. 207) fala por isso de "uma influência da desigualdade estrutural sobre os estilos de vida [...] em cujo âmbito se origina uma pluralidade de estilos de vida”.

Os efeitos genéricos de mobilidade revelados através destes resultados, contudo, são relativamente opacos. É bem verdade que a relevância dos estilos de vida para processos sociais de seleção e sua influência para o posicionamento social dos indivíduos é por eles revelada. Mas não fica claro em que medida as opções por um estilo de vida efetivamente podem ser aproveitadas para a ascensão social ou, por outro lado, se as escolhas correspondentes atingem e influenciam decisivamente o posicionamento e os processos de mobilidade descendente no espaço de posições sociais. O que os resultados mostram claramente é uma pluralização e, com isso, uma individualização das preferências estéticas cotidianas e, para além disso, uma influência na orientação ascendente das camadas médias.

Modelos estéticos cotidianos e variantes na busca por estilos de vida são tema secundário para Olaf Groh-Samberg (2004; 2005) em seu estudo sobre a relação entre pobreza e estrutura social, feito com base nos dados do "Painel Sócio-econômico" (Soep) dos anos 1996-2000. Em distanciamento e crítica à pesquisa dinâmica sobre pobreza, que vem diagnosticando uma temporalização, individualização e desvinculação social da pobreza (Leibfried et al., 1995; Berger, 1994), a pobreza é concebida como multidimensional e operacionalizada através da renda disponível e da dimensão condições de vida tamanho da moradia, equipamentos domésticos, desemprego, reservas materiais e recebimento de ajuda social. Em oposição às teses de uma temporalização e desvinculação da pobreza por um lado e a constatação de uma divisão e exclusão duradouras através da pobreza (Kronauer, 2002) por outro, GrohSamberg (2005) parte do pressuposto que flutuações temporárias em determinadas dimensões da condição de vida e da renda sejam maiores que mudanças no conjunto das condições de vida. Além disto, ele suspeita que no longo prazo as condições de vida em seu conjunto sejam estruturadas pelas classes sociais. Em sua análise sobre a relação entre renda, condição de vida e 
duração do tempo ele identifica um total de cinco zonas: bem-estar, precarização temporária ou unilateral, ${ }^{5}$ situações inconsistentes de pobreza, precariedade $^{6}$ e pobreza duradoura e múltipla. O estudo mostrou, ademais, que entre $6 \%$ e $7 \%$ de todas as pessoas vivem em situação de pobreza duradoura e múltipla, e com isso se encontram na posição de exclusão estrutural. Além destes, somam-se à zona da "precariedade" entre $21 \%$ e $25 \%$. De acordo com estes dados, nem uma renda média ou alta pode evitar continuamente condições precárias de vida ou pobreza, tampouco as condições instáveis de vida em diversas dimensões têm sempre como conseqüência uma situação de pobreza. Também fica claramente demonstrado ser mais freqüente constatar empiricamente a pobreza unidimensional devida à renda do que devida, de forma unilateral, às condições de vida. Quando se relacionam estes dados com as posições de classe social, operacionalizadas segundo John H. Goldthorpe (2003) como classes profissionais, então se constata serem sobretudo famílias de trabalhadores com histórico de migração e lares uniparentais os mais expostos ao risco de pobreza. Mesmo que os efeitos de classe se reduzam claramente quando se leva em consideração a etnicidade, desaparecendo inclusive no caso dos lares uniparentais, constata-se, de um modo geral, uma relação entre classe e risco de pobreza. Divergindo da interpretação de O. Groh-Samberg (2005, p. 674), mas valendo-se dos mesmos dados, é possível apontar que ainda que a pobreza siga se constituindo transgeracionalmente vinculada especificamente às classes, existem diferentes opções para ascensão e riscos de decadência. Os resultados mostram que mesmo nas camadas superiores do funcionalismo não está assegurado um bem-estar duradouro para um quarto das pessoas.

Mas esta constatação não pode ser generalizada e referida como prova de uma desestruturação fundamental e consistente da relação entre influências específicas da classe, status profissional e condições atuais de vida - pelo menos não enquanto se segue a tese da individualização de Ulrich Kohler em

5 Pessoas apresentam fortes oscilações ou condições precárias persistente em uma das duas dimensões da pobreza - renda, condição de vida -, mas assumem na outra dimensão uma condição bem segura (Groh-Samberg, 2005).

6

Em sintonia com Walter Hanesch et al. (1994), O. Groh-Samber entende haver precariedade, em distinção a precarização, quando "situações precárias em pelo menos uma dimensão estão estabilizadas temporalmente e praticamente não surgem mais condições seguras” (GrohSamberg, 2005, p. 655). 
sua pesquisa sobre a relação entre bem-estar crescente, inconsistências de status e desestruturação das situações de vida, compreendida como relação entre classe e condições favoráveis ou desfavoráveis de vida (Kohler, 2005; Stein, 2005; Hartmann, 1998). Com base nos "European Quality of Life Studies” (Eqls), que acolhe dados de 28 países, pode-se constatar nos países mais ricos da Europa, contrariamente às expectativas, uma cristalização do status relativo a renda, formação e profissão, interpretada por U. Kohler (2005, p. 242) como efeito da função de alocação dos respectivos sistemas de formação (Fend, 2006a). A já conhecida situação de uma inflação na formação nas sociedades ricas, pela qual a participação de amplas camadas da população na formação superior resulta numa desvalorização dos certificados de formação, e onde posições melhores no mercado de trabalho são acessíveis tão somente com titulações mais altas, fica claramente documentada com os dados. Contudo, ao concentrar-se em pessoas ocupadas, a pesquisa não leva em consideração as pessoas com alto nível de formação fracassadas no mercado de trabalho. Com isso se eclipsa o fato que os certificados de formação obtidos têm cada vez menos capacidade de garantir um bom posicionamento (Mertens, 1984) e que a função de alocação da escola, no sentido de atribuir status socialmente legitimado (Parsons, 1971), está sendo enfraquecida. Além disto, os processos de reforço da desigualdade durante a carreira escolar e as diferentes chances para a obtenção dos mais elevados certificados de formação moldadas pelas diferenças nos contextos de origem não são refletidos sistematicamente na fundamentação nem acolhidos na análise. Não foi levado em consideração que a família de origem, a despeito de as chances e barreiras para a formação terem se alterado (Büchner, 2003), constitui-se em uma variável central para carreiras de formação e qualificação - isto é, que existe uma clara relação entre a pertinência a determinada camada ou grupo, condições sociais, recursos de capital social e orientações sócio-culturais, assim como formas de aquisição de competências (Büchner, 2003; Schlüter, 1999; Baumert et al., 2003; Watermann e Baumert, 2006)- como tampouco se levou em consideração o fato que as decisões relativas a transições na formação escolar e profissional são muito influenciadas pelo contexto social de origem, que orientações para a carreira escolar dependem da origem e que pais oriundos de contextos com baixa aspiração em termos de formação mais freqüentemente advogam contra carreiras de formação de longo prazo do que aqueles pais inseridos em contextos com aspiração elevada (Thole, Cloos e Rietzke, 2006, p. 309). 
Esta constatação central ecoa também no estudo apresentado por Werner Georg (2005). ${ }^{7}$ Em conexão com conhecimentos anteriores, a aquisição familiar de capital cultural é diferenciada em consumo de produtos da alta cultura, que são usados sobretudo por camadas mais elevadas como marcadores e sinais distintivos para a reprodução social, e a cultura familiar da leitura, que, como recurso cognitivo e lingüístico, facilita o sucesso das crianças no sistema público de formação. As chances para a incorporação de capital cultural na socialização extra-escolar são operacionalizadas por W. Georg (2005) através das dimensões "conversas sobre cultura e política entre pais e filho", "práxis cultural do filho" e "cultura familiar de leitura”. Estes fatores, juntamente com o nível de formação dos pais, são analisados em sua influência sobre o nível de formação, a primeira ocupação e a atual ocupação do filho. A pesquisa mostra um efeito de transmissão direto entre o nível de formação dos pais e o do filho. O segundo maior fator de influência é a cultura de leitura dos pais, igualmente influenciada por seu nível de formação. Com isso fica amplamente documentada uma trilha reprodutiva fechada que vai do nível de formação dos pais, passa pela cultura de leitura dos pais, influencia o nível de formação da criança e vai além, até a escolha e o desempenho na primeira e segunda ocupação profissional. Conversas comuns sobre cultura e política entre pais e filhos, contudo, não revelam influência significativa sobre a carreira de formação e ocupação, mas sim sobre as práticas culturais exercidas pelos filhos. Aqui fica clara a relevância dos contextos informais de socialização para uma carreira de formação escolar bem sucedida e para o desenvolvimento de mobilidade social. Não está definido, no entanto, se são prima-

7 No centro desta pesquisa, que igualmente toma como ponto de partida o conceito de habitus de Bourdieu, está o exame da exigente seleção social do sistema de formação alemão, tendo como base os dados de uma pesquisa feita em Konstanz intitulada "Trajetórias de vida de jovens adultos” (LiFE - Fend, 2006b). A pesquisa examina a influência do capital cultural sobre os efeitos de posicionamento relevantes para a desigualdade na trajetória de vida mediante um estudo longitudinal entre o $16^{\circ}$ e $35^{\circ}$ ano de vida. W. Georg (2005, p. 181) operacionaliza a dimensão do capital social em capital incorporado - aquela formação quase corporalmente inscrita no indivíduo -, objetivado - objetos como livros -, e institucionalizado expresso em certificados de formação. Na pesquisa parte-se de uma distribuição desigual do capital cultural, que é pressuposto implicitamente justamente pelas escolas superiores para cursá-las com sucesso. O sucesso na formação torna-se assim o encaixe entre capital cultural incorporado da família de origem e exigências institucionalmente impostas de aquisição de capital cultural institucionalizado (sobre cultura escolar, ver Helsper et al., 2001; sobre o encaixe entre cultura escolar e biografia de alunos, ver. Idel, 2004 e Kramer, 2002). 
riamente os processos informais de aprendizagem, a retaguarda social e sua influência sobre a vontade de estudar ou se são outros efeitos que desempenham aqui um importante papel. Mas fica claro que a reprodução intergeracional do capital cultural (Szydlik, 2004) e sua importância para a carreira de formação e profissão são estruturadas, essencialmente, de forma direta, pelo nível de formação dos pais e pela cultura familiar de leitura, por ela muito influenciada. As práticas da alta cultura, em contrapartida, não têm efeito direto e servem antes como prática distintiva. A pesquisa de W. Georg (2005) confirma uma vez mais as chances significativamente melhores de filhos de pais bem sucedidos em relação à obtenção de uma titulação acadêmica mais elevada e, posteriormente, a correlata obtenção de posições correspondentes na vida profissional com elevado prestígio social. Em divergências com as expectativas (Stein, 2005), práticas da alta cultura desempenham um papel apenas subordinado em relação à clara influência de uma cultura familiar de leitura, que consegue reforçar as habilidades lingüísticas e cognitivas da criança.

A importância do envolvimento em redes de relações com pessoas da mesma idade em relação à conclusão bem-sucedida de carreiras de formação escolar até o momento é tão subestimado quanto a preferência por determinadas atividades de lazer (Zinnecker, 1985; Büchner e Brake, 2006; Stecher, 2005). Pelo menos isto é o que revelam os resultados da pesquisa publicada por Bettina Isengard (2005), que revelam uma relação estreita entre recursos econômicos e estilo de vida, que ela define conceitualmente como comportamento de lazer, tendo como base de dados o Painel Sócio-Econômico (Soep) de 1990 e 2003. Na análise da influência de renda, formação, idade e gênero sobre as formas de lazer fica evidente que os fatores de desigualdade de renda e formação exercem uma influência significativa sobre as práticas de lazer elegidas. Ainda que de um modo geral a importância da formação sobre o comportamento preferido de lazer venha diminuindo, percebe-se antes uma equiparação dos grupos superiores de formação com os intermediários; por conseguinte, seguem subsistindo diferenças no comportamento de lazer entre os grupos com diferentes níveis de formação, que se expressam, sobretudo, no âmbito da aceitação da "alta cultura". Os resultados correspondem aos obtidos por P. Stein (2005) na medida em que o consumo da alta cultura é utilizado pelas classes superiores como prática social distintiva. Também aqui são justamente as camadas inferiores em termos de formação as que menos participam dos processos sociais de desestruturação. Mais 
drásticas se revelam as diferenças estruturais em relação à renda. De um modo especial a orientação para a aventura e as atividades de alta cultura não apenas têm forte relação com a renda, mas a influência do capital econômico inclusive é crescente com o passar do tempo. Se a disponibilidade de recursos materiais regula as possibilidades sociais de participação na vida pública e no poder político e cultural, então com alguma razão talvez se possa até supor que precisamente através desta correlação se formem processos de exclusão; ou seja, pessoas de condições econômicas de vida mais limitadas são excluídas da participação social como cidadãos (Bourdieu, 1997). "O modo individual de organizar o lazer ou o estilo de vida reflete, portanto, a posição na trama da desigualdade social” e reforça e legitima desigualdade social (Isengard, 2005, p. 257).

\section{Rumo a uma outra sociedade? Balanço intermediário}

Os resultados são díspares, pelo menos com relação a uma individualização claramente manifesta das orientações sócio-culturais e uma flexibilização claramente derivada das aspirações com relação à formação, aos modos de comportamento no lazer e às preferências de estilos de vida; os caminhos em direção à "segunda modernidade" parecem realmente mais acidentados do que se imaginava. As pesquisas mostram que em relação ao comportamento no lazer, aos estilos de vida, às trajetórias de formação e da pobreza, no transcurso da vida, assim como à interdependência entre condições de vida, renda, pobreza e posição de status, ocorreu uma individualização e uma desestruturação parcial, com simultânea persistência das desigualdades estruturais. Este ganho em flexibilidade e mobilidade, no entanto, se concentra, sobretudo, nas pessoas pertencentes aos grupos sociais tipicamente médios. A tese da teoria da modernização sobre o aumento de riscos e condições problemáticas independentemente de classe é mais claramente apoiada pelas análises da relação entre situação de classe, bem-estar social e situação de vida nas dimensões satisfação com a vida, qualidade de vida e finanças ainda que as classes inferiores dos trabalhadores sem ou com pouca qualificação sejam as mais insatisfeitas com sua vida, é possível constatar que, “de um modo geral, a presente análise aponta claramente para a desestruturação das condições de vida” (Kohler, 2005, p. 248). 
A imagem criada por P. A. Berger e M. Vester (1998) com o título de sua coletânea sobre "Velhas desigualdades, novas divisões" (Alte Ungleichheiten, neue Spaltungen) também se reflete nas pesquisas atuais. São as camadas superiores e, sobretudo, as médias que, de fato, se mostram orientadas pluralmente em seus estilos de vida (Stein, 2005), em relação às condições de pobreza (Groh-Samberg, 2005) e com vistas a sua situação de vida (Kohler, 2005) e que têm mobilidade. Em contraste, as camadas pobres em recursos econômicos e sócio-culturais raramente participam das opções sociais de mobilidade, que pudessem se manifestar como ganhos em potencial de individualização. As pessoas com baixa renda e com condições de vida mais expostas aos riscos seguem sendo as mais atingidas pela pobreza (Groh-Samberg, 2005), são as menos satisfeitas (Kohler, 2005), fazem significativamente menos uso de seu direito à participação política e estão estruturalmente mais afastadas da participação na alta cultura e nas atividades comerciais de lazer voltadas à aventura (Isengard, 2005). Ainda que, pelo menos na pesquisa de W. Georg (2005), não esteja comprovada uma relação entre a afinidade pela práxis da alta cultura e o sucesso na formação dos adolescentes, o fator "herança social”, expresso como nível de formação dos pais e como cultura familiar de leitura dele derivado (Georg, 2005), é significativamente relevante e é fortemente secundado pelas análises dos estudos comparativos internacionais sobre formação escolar (Baumert, Stanat e Watermann, 2006).

Portanto, processos de individualização e pluralização em algumas dimensões não podem ocultar o fato que pessoas participantes em grupos, classes e camadas sociais com baixa escolaridade e com parca dotação de recursos materiais e sócio-culturais continuam não participando de maneira abrangente dos recursos socialmente disponíveis em diversos âmbitos estruturalmente definidos e são parcialmente atingidas por formas extensas de exclusão (Kronauer, 2002; Castell, 2005). Como em especial documenta a pesquisa de O. Groh-Samberg (2005), não se pode desconhecer uma relação entre situação de classe - definida através do status ocupacional -, condições de vida, renda e pobreza e a ameaça daí decorrente de marginalização social. Contudo, não são apenas as pessoas que já se encontram em situação de pobreza que estão ameaçadas de exclusão, mas também e talvez em especial aquelas pessoas que foram atingidas por uma precarização de suas condições de vida, 
a despeito de eventual ocupação econômica (Strengmann-Kuhn, 2000), ou já se encontram em condições precárias - e que, segundo O. Groh-Samberg (2005, p. 670), perfazem aproximadamente $40 \%$ da população em idade ativa. Em outras palavras: desigualdades sociais, não podem ser definidas mais apenas com base em classes e camadas sociais, uma vez que também "pessoas pertencentes a grupos sociais parciais e periféricos discriminados (ou privilegiados) são atingidas” pela desigualdade social (Kreckel, 1992, p. 17).

Estas constatações correspondem com aquelas feitas por Heinz Bude e Ernst-Dieter Lantermann (2006). Como resultado central de sua pesquisa sobre a percepção de exclusão eles concluem que "a forma como o indivíduo se comporta em relação ao todo imaginário da sociedade [...] não é simplesmente expressão de sua situação social. [...] Há uma diferença entre aqueles que a despeito de suas precárias condições de vida se sentem bem no mundo social e aqueles que, mesmo em condições de vida favoráveis, são dominados pela dúvida, se eles ainda têm um lugar no conjunto da sociedade” (Bude e Lantermann, 2006, p. 20). Não obstante, também esta conclusão requer precaução, uma vez que explicitamente se discutem os processos de etiquetamento individualizado, da adscrição individual de responsabilidade e culpa por situações sociais, assim como das formas correlacionadas de "sublimação" das condições de vida com o propósito de compensar estas mesmas adscrições. Concretamente e a título de exemplo: o desempregado individualmente, na perspectiva da opinião pública majoritária, não aparece como vítima de condições sócio-econômicas concretas, mas como "autor" de sua situação de vida liberada do trabalho. Por conseqüência, a "perda do trabalho ou o fracasso na biografia é avaliado como apartamento do modelo de normalidade [...], como ‘fracasso' e ‘desvio'” (Münchmeier, 1996, p. 147; Walther, 2002). O pressuposto da própria culpa assim influenciado vale, especialmente, para pessoas em condições marginalizadas de vida; eventualmente, tem aqui como resultado a não-tematização dos etiquetamentos socialmente induzidos, no sentido de perceber-se como auto-responsável. ${ }^{8}$

8 Os efeitos correlatos a esta questão contudo não são tematizados na pesquisa de H. Bude e E.-D. Lantermann (2006). Se a marginalização é experimentada devido à ausência ou à insuficiência de capital econômico e cultural e se um modelo de interpretação da "culpa" individual for desenvolvido, então é provável que este modelo é quase excluído na comunicação e por conseqüência, “destruído”. 
Se confrontarmos este esboço da situação da sociedade com os resultados de pesquisas revistos e discutidos anteriormente, então por um lado se confirma em maior ou menor grau o diagnóstico, e, por outro, é também confrontado com dados empíricos que minam a univocidade do diagnóstico e o questionam. Em especial o suposto de uma individualização disseminada, isto é, um ganho em autonomia para todos os grupos populacionais, só tem como base resultados empíricos muito inseguros. Tendências à individualização, no sentido de diluição da dependência de adscrições das chances e aspirações de formação, das preferências de estilo de vida culturalestéticas e das preferências de lazer, de modo algum se revelam generalizadas, pelo menos não nas pesquisas aqui discutidas (Kohler, 2005; Georg, 2005; Stein, 2005; Isengard, 2005). Elas são válidas, no máximo, para os grupos sociais centrais com renda média e uma nítida orientação voltada à formação. Para estes grupos sociais centrais é possível constatar um ganho em mobilidade e uma pluralização, respectivamente uma desestruturação dos estilos de vida, mas também um aumento de riscos e problemas sociais, que podem ser documentados com tendências à precarização do "núcleo central da sociedade”, ou com o perigo estrutural desta precarização (GrohSamberg, 2004). Tampouco está comprovada uma reprodução generalizada, dispersa por todos os segmentos sociais, da desigualdade social através da variável pertinência a uma classe; ela é demonstrada empiricamente com apenas alguma evidência para aquelas pessoas com baixa renda e distantes da alta cultura estética e dos bens culturais. Ganhos em mobilidade social, formas e tendências de desestruturação das orientações estético-culturais, dos estilos de vida e das preferências de lazer, moldadas pelo status e pela classe - ou seja, ganhos em termos de flexibilizações dinâmicas, que podem ser sintetizadas na categoria "individualização" -, revelam-se, conforme já exposto, de forma mais expressiva nos grupos e classes sociais intermediários e superiores (Klein, Landhäußer e Ziegler, 2005, p. 61; Vester et al., 2001). Não obstante, parece que de modo algum foi interrompida a silente persistência da sociedade de classes oculta sob o vocabulário da "individualização", degradado a uma metáfora ideológica. Mais expressiva talvez ainda seja a descrição ambivalente contida no discurso sobre "a sociedade concorrencial, segmentada e dividida”. O conceito reflete o fato destacado, segundo o qual as tendências de individualização de modo 
algum podem ser constatadas como onipresentes, como tampouco o é a diferenciada e instável "situação social de concorrência", que é determinante, mas não leva à formação nova de blocos clássicos de classe - "nem em sentido material, nem em sentido simbólico" (Lessenich e Nullmeier, 2006, p. 19). A sociedade da República Federal da Alemanha do início do século 21 é "diferente” daquela do século 20 - ainda que não tão "diferente” quanto ocasionalmente admitido em folhetins e debates pós-modernos.

A ambivalente forma de "cabeça de Janus" da moderna sociedade da República Federal da Alemanha, em sua complexidade e "inconclusividade", em sua "novidade", não pode mais ser descrita abrangentemente com os modelos teóricos dos séculos 19 e 20. Parece ser necessária uma “reorientação categorial” (Beck e Lau, 2005, p. 113) e teórica, que reflita as realidades empíricas, para dar conta dos novos ajustamentos da sociedade. Se as análises disponíveis forem levadas a sério, então inexiste uma concepção teórica "clara” do novo - pelo menos não caso seja possível concordar com a avaliação de que as matrizes descritivas de interpretações monocausais e unidimensionais e os enfoques causais são estruturalmente muito rígidos para codificar teoricamente as mudanças sociais. Há muitos indicativos que apontam para a necessidade de "se pensar o novo [...] segundo o princípio do 'tanto-quanto"”, porque ele não "surge em sua forma pura, mas em diferentes e múltiplas configurações” (Beck, Bonß e Lau, 2004, p. 32).

Os desenvolvimentos sociais discutidos não têm apenas importância para as discussões acadêmicas sobre o "estado da sociedade" mas têm relevância, por exemplo, para as reflexões da pedagogia escolar, da pedagogia social e do serviço social. Eles podem estimular as discussões sociológicas e de teoria social assim como os discursos e as práticas nas esferas social e pedagógica a repensarem tradições, perspectivas e explicações "encasteladas” sobre a estrutura social e dinâmica, sem desautorizar os conhecimentos e experiências relacionados com as respectivas tradições. 


\section{Referências}

Allgemeinen Bevölkerungsumfrage der Sozialwissenschaften (ALLBUS), disponível em: www.social-science-gesis.de/Dauerbeobachtung/Allbus/.

ANHORN, R. Zur Einleitung: Warum sozialer Ausschluss für Theorie und Praxis Sozialer Arbeit zum Thema werden muss. In: ANHORN, R. e BETTINGER, F. (Orgs.). Sozialer Ausschluss und Soziale Arbeit. Positionsbestimmungen einer kritischen Theorie und Praxis Sozialer Arbeit. Wiesbaden: VS, Verlag für Sozialwissenschaften, 2005, p. 11-41.

ANHORN, R. e BETTINGER, F. (Orgs.). Sozialer Ausschluss und Soziale Arbeit. Positionsbestimmungen einer kritischen Theorie und Praxis Sozialer Arbeit. Wiesbaden: VS, Verlag für Sozialwissenschafte, 2005.

BAUMERT, J. u. a. Disparitäten der Bildungsbeteiligung und des Kompetenzerwerbs. In: Zeitschrift für Erziehungswissenschaft, v. 6, n. 1, 2003, p. 64-73.

BAUMERT, J.; STANAT, P. e WATERMANN, R. (Orgs.). Herkunftsbedingte Disparitäten im Bildungswesen. Vertiefende Analysen im Rahmen von PISA 2000. Wiesbaden:VS, Verlag für Sozialwissenschaften, 2006.

BECK, U. Risikogesellschaft. Auf dem Weg in eine andere Moderne. Frankfurt am Main: Suhrkamp, 1986.

BECK, U. e LAU, Ch. Theorie und Empirie reflexiver Modernisierung. Von der Notwendigkeit und den Schwierigkeiten, einen historischen Gesellschaftswandel innerhalb der Moderne zu beachten und zu begreifen. In: Soziale Welt, v. 56. n. 2/3, 2005, p. 107-135.

BECK, U.; BONß, W. e LAU, Ch. Entgrenzung erzwingt Entscheidung. In: BECK, U. e LAU, Ch. Entgrenzung und Entscheidung. Frankfurt am Main: Suhrkamp, 2004, p. 13-63.

BERGER, P. A. Individualisierung und Armut. In: ZWICK, M. M. (Org.). Einmal arm - immer arm? Neue Befunde zu Armut in Deutschland. Frankfurt am Main e New York: Campus,1994, p. 21-46.

BERGER, P. A. Individualisierung. Zwischen Statusunsicherheit und Erfahrungsvielfalt. Opladen: Verlag Leske + Budrich, 1996.

BERGER, P. A. e VESTER, M. Alte Ungleichheiten - Neue Spaltungen. In: BERGER, P. A. e VESTER, M. Alte Ungleichheiten - Neue Spaltungen. Opladen: Verlag Leske + Budrich, 1998, p. 9-28.

BIELING, H.-J. Dynamiken sozialer Spaltung und Ausgrenzung. Gesellschaftstheorien und Zeitdiagnosen. Münster: Westfälisches Dampfboot, 2000.

BOCK, K. Bildungsprozesse als Chance - auch was für Benachteiligte? In: AFET Bundesverband für Erziehungshilfe (Org.). Erziehungshilfe fördert Chancen. Bildung statt Benachteiligung. Hannover: AFET, 2005, p. 189-207. 
BÖHNISCH, L. e SCHRÖER, W. Stichwort: Soziale Benachteiligung und Bewältigung. In: Zeitschrift für Erziehungswissenschaft, v. 7, n. 4, 2004, p. 467-478.

BOTHMER, von H. e FÜLBIER, P. Ansätze zur Weiterentwicklung der Berufsausbildung Benachteiligter. In: FÜLBIER, P. e MÜNCHMEIER, R. (Orgs.). Handbuch Jugendsozialarbeit. v. 1. Münster: Votum, 2001, p. 504-515.

BOURDIEU, P. Die feinen Unterschiede. Kritik der gesellschaftlichen Urteilskraft. Frankfurt am Main: Suhrkamp, 1982.

BOURDIEU, P. Ökonomisches Kapital, kulturelles Kapital, soziales Kapital. In: REINHARD e KRECKEL (Orgs.). Soziale Ungleichheiten. Soziale Welt, Sonderheft 2. Göttingen: Schwartz, 1983, p. 183-198.

BOURDIEU, P. Sozialer Raum und “Klassen”. Frankfurt am Main: Suhrkamp, 1985.

BOURDIEU, P. Die männliche Herrschaft. In: DÖLLING, I. e KRAIS, B. (Orgs.). Ein alltägliches Spiel. Geschlechterkonstruktion in der sozialen Praxis. Frankfurt a. Main: Suhrkamp, 1997, p. 153-216.

BÜCHNER, P. Stichwort: Bildung und Soziale Ungerechtigkeit. In: Zeitschrift für Erziehungswissenschaft, v. 6, n. 1, 2003, p. 5-25.

BÜCHNER, P. e BRAKE, A. Bildungsort Familie. Wiesbaden: VS, Verlag für Sozialwissenschaften, 2006.

BUDE, H. e LANTERMANN, E.-D. Soziale Exklusion und Exklusionsempfinden. Kassel (MS), 2006.

CASTELL, R. Die Stärkung des Sozialen. Leben im neuen Wohlfahrtsstaat. Hamburg: Hamburger Edition, 2005.

COLLINGRO, P. e JAKOB, J. Die Benachteiligtenförderung in Ungarn - Beispiel für binationale Kooperationen. In: FÜLBIER, P. e MÜNCHMEIER, R. (Orgs.). Handbuch Jugendsozialarbeit. v. 1. Münster: Votum, 2001, p. 699-708.

DAHRENDORF, R. Wenn der Arbeitsgesellschaft die Arbeit ausgeht. In: MATTHES, J. (Org.). Krise der Arbeitsgesellschaft? Verhandlungen des 21. Soziologentages in Bamberg. Frankfurt am Main: Suhrkamp,1983, p. 25-37.

DEPPE, F. Globalisierung und Ausgrenzung. In: ANHORN, R. e BETTINGER, F. (Orgs.). Sozialer Ausschluss und Soziale Arbeit. Positionsbestimmungen einer kritischen Theorie und Praxis Sozialer Arbeit. Wiesbaden: VS, Verlag für Sozialwissenschaften, 2005, p. 45-55.

ERLINGHAGEN, M. e KNUTH, M. Arbeitsmarktdynamik zwischen öffentlicher Wahrnehmung und empirischer Realität. In: WSI Mitteilungen, v. 56, n. 8, 2003, p. 505-509.

FEND, H. Neue Theorie der Schule. Einführung in das Verstehen von Bildungssystemen. Wiesbaden: VS, Verlag für Sozialwissenschaften, 2006a. 
FEND, H. Bildungserfahrungen und produktive Lebensbewältigung - Ergebnisse der LifE-Studie. In: FATKE, R. e MERKENS, H. (Orgs.). Bildung über die Lebenszeit. Wiesbaden: VS, Verlag für Sozialwissenschaften, 2006b, p. 31-56.

GEORG, W. Reproduktion sozialer Ungleichheit im Lebenslauf. In: Zeitschrift für Soziologie der Erziehung und Sozialisation, v. 25, n. 2, 2005 , p. 178-197.

GOLDTHORPE, H. J. Globalisierung und soziale Klasse. In: MÜLLER, W. e SCHRER, St. (Orgs.). Mehr Risiken - Mehr Ungleichheit? Abbau von Wohlfahrtsstaat, Flexibilisierung von Arbeit und die Folgen. Frankfurt am Main e New York: Campus, 2003, p. 31-62.

GORZ, A. Abschied vom Proletariat. Frankfurt am Main: Suhrkamp, 1980.

GROH-SAMBERG, O. Armut und Klassenstruktur. Zur Kritik der Entgrenzungsthese aus einer multidimensionalen Perspektive. In: Kölner Zeitschrift für Soziologie und Sozialpsychologie, v. 56, n. 4, 2004, p. 653-682.

GROH-SAMBERG, O. Die Aktualität der sozialen Frage - Trendanalysen sozialer Ausgrenzung 1984-2004. In: WSI-Mitteilungen, v. 58, n. 11, 2005, p. 616-623.

HANESCH, W. u. a. Armut in Deutschland (Armutsbericht des DGB und des Paritätischen Wohlfahrtsverbandes). Reinbeck b. Hamburg: Rowohlt, 1994.

HARTMANN, M. Homogenität und Stabilität. Die soziale Rekrutierung der deutschen Wirtschaftselite im europäischen Vergleich. In: BERGER, P. A. e VESTER, M. Alte Ungleichheiten - Neue Spaltungen. Opladen: Verlag Leske + Budrich, 1998, p. 171-188.

HELSPER, W. u. a. Schulkultur und Schulmythos. Rekonstruktionen zur Schulkultur 1. Opladen: Verlag Leske + Budrich, 2001.

HERKOMMER, S. Sozialstaat und Klassengesellschaft. Zur Reproduktion sozialer Ungleichheit im Spätkapitalismus. In: KRECKEL, R. (Org.). Soziale Ungleichheit. Soziale Welt, Sonderband 2. Göttingen: Schwartz, 1983, p. 75-92.

HERKOMMER, S. Ausgrenzung und Ungleichheit. Thesen zum neuen Charakter unserer Klassengesellschaft. In: ANHORN, R. e BETTINGER, F. (Org.). Sozialer Ausschluss und Soziale Arbeit. Positionsbestimmungen einer kritischen Theorie und Praxis Sozialer Arbeit. Wiesbaden: VS, Verlag für Sozialwissenschaften, 2005, p. 57-65.

HRADIL, St. Soziale Ungleichheit in Deutschland. Wiesbaden: VS, Verlag für Sozialwissenschaften, 2005.

IDEL, T.-S. Waldorfschulen als Sphären biographischer Entwicklung. Inauguraldissertation am Fachbereich Pädagogik der Universität Mainz,2004.

ISENGARD, B. Freizeitverhalten als Ausdruck sozialer Ungleichheiten oder Ergebnis individualisierter Lebensführung? Zur Bedeutung von Einkommen und Bildung im Zeitverlauf. In: Kölner Zeitschrift für Soziologie und Sozialpsychologie, v. 57, n. 2, 2005, p. 254-277. 
KELLER, B. e SEIFERT, H. Atypische Beschäftigungsverhältnisse - Flexibilität, soziale Sicherheit und Prekarität. In: WSI Mitteilungen, v. 59, n. 8, 2006, p. 235-240.

KLEIN, A.; LANHHÄßER, S. e ZIEGLER, H. The Salient Injuries of Class. Zur Kritik der Kulturalisierung struktureller Ungleichheit. In: Widersprüche, v. 58, n. 98, 2005, p. 45-74.

KOHLER, U. Statusinkonsistenz und Entstrukturierung von Lebenslagen. Empirische Untersuchung zweier Individualisierungshypothesen mit Querschnittsdaten aus 28 Ländern. In: Kölner Zeitschrift für Soziologie und Sozialpsychologie, v. 57, n. 2, 2005, p. 230-253.

KRAMER, R.-T. Das "schulbiographische Passungsverhältnis”. Hermeneutische Rekonstruktionen zum Verhältnis von Schülerbiografie und Schulkultur. Opladen: Verlag Leske + Budrich, 2002.

KRECKEL, R. Theorien sozialer Ungleichheit im Übergang. In: KRECKEL, R. (Org.). Soziale Ungleichheit. Soziale Arbeit, Sonderband 2. Göttingen: Schwartz, 1983, p. 3-12.

KRECKEL, R. Politische Soziologie der Ungleichheit. Frankfurt am Main: Suhrkamp, 1992.

KRECKEL, R. Klassentheorie am Ende der Klassengesellschaft. In: BERGER, P. A. e VESTER, M. (Orgs.). Alte Ungleichheiten - Neue Spaltungen. Opladen: Verlag Leske + Budrich, 1998, p. 31-48.

KRONAUER, M. Exklusion. Die Gefährdung des Sozialen im hoch entwickelten Kapitalismus. Frankfurt am Main e New York: Campus, 2002.

LEIBFRIED, St. u. a. Zeit der Armut. Lebensläufe im Sozialstaat. Frankfurt am Main: Suhrkamp, 1995.

LESSENICH, St. e NULLMEIER, F. Einleitung - Deutschland zwischen Einheit und Spaltung. In: LESSENICH, St. e NULLMEIER, F. (Orgs.). Deutschland eine gespaltene Gesellschaft. Frankfurt am Main: Suhrkamp, 2006, p.7-26.

MACKERT, J. (Org.). Die Theorie sozialer Schließung. Traditionen, Analysen, Perspektiven. Wiesbaden: VS, Verlag für Sozialwissenschaften, 2004.

MARX, K. Das Kapital. Berlin: Dietz, 1974.

MERTENS, D. Das Qualifikationsparadox. In: Zeitschrift für Pädagogik, v. 84, n. 4, 1984, p. 439-456.

MÜNCHMEIER, R. Zwischen Erziehung und Politik. Anmerkungen zur Jugendberufshilfe in Ostdeutschland. In: MÜNDER, J. e JORDAN, E. (Orgs.). Mut zur Veränderung. Münster: Votum, 1996, p. 145-154.

NAMUTH, M. “San Precario, bitte uns”. In: Mitbestimmung, n. 12, 2006, p. 34.

OTTO, Hans-Uwe e ZIEGLER, Holger. Managerielle Wirkungsorientierung un der demokratische Nutzwert professioneller Sozialer Arbeit. Opladen: VS Verlag, 2005. 
PARSONS, T. Die Schulklasse als soziales System. In: RÖHRS, H. (Org.). Der Aufgabenkreis der pädagogischen Soziologie. Frankfurt am Main: Suhrkamp, 1971, p. 154-179.

SCHLÜTER, A. Bildungserfolge. Eine Analyse der Wahrnehmungs- und Deutungsmuster und der Mechanismen für Mobilität in Bildungsbiographien. Opladen: Verlag Leske + Budrich, 1999.

SCHULZE, G. Die Erlebnisgesellschaft. Kultursoziologie der Gegenwart. Frankfurt am Main: Suhrkamp, 1992.

STECHER, L. Informelles Lernen bei Kindern und Jugendlichen und die Reproduktion sozialer Ungleichheit. In: Zeitschrift für Erziehungswissenschaft, v. 68, n. 3, 2005, p. 347-392.

STEIN, P. Soziale Mobilität und Lebensstile. In: Kölner Zeitschrift für Soziologie und Sozialpsychologie, v. 57, n. 2, 2005, p. 205-229.

STRENGMANN-KUHN, W. Erwerbstätigkeit und Einkommensarmut. In: BÜCHEL, F. u. a. (Org.). Zwischen drinnen und draußen. Opladen: Verlag Leske + Budrich, 2000, p. 139-152.

SZYDLIK, M. Generation und Ungleichheit. Wiesbaden: VS, Verlag für Sozialwissenschaften, 2004.

THOLE, W.; CLOOS, P. e RIETZKE, T. "Bildungsbremse" Herkunft. Zur Reproduktion sozialer Ungleichheit im Vorschulalter In: OTTO, H.-U. e OELKERS, J. (Orgs.). Zeitgemäße Bildung. Herausforderung für Erziehungswissenschaft und Bildungspolitik. München: Reinhardt, 2006, p. 287-315.

VESTER, M. u. a. Soziale Milieus im gesellschaftlichen Strukturwandel: Zwischen Integration und Ausgrenzung. Köln: Bund-Verlag, 1993.

VESTER, M. u. a. Soziale Milieus im gesellschaftlichen Strukturwandel. Zwischen Integration und Ausgrenzung. Frankfurt am Main: Suhrkamp, 2001.

WALTHER, A. "Benachteiligte Jugendliche”: Widersprüche eines sozialpolitischen Deutungsmuster. Anmerkungen aus einer europäisch-vergleichenden Perspektive. In: Soziale Welt, v. 53. n. 1, 2002, p. 87-106.

WATERMANN, R. e BAUMERT, J. Entwicklung eines Strukturmodells zum Zusammenhang zwischen sozialer Herkunft und fachlichen und überfachlichen Kompetenzen: Befunde national und international vergleichender Analysen. In: BAUMERT, J.; STANAT, P. e WATERMANN, R. (Orgs.). Herkunftsbedingte Disparitäten im Bildungswesen. Vertiefende Analysen im Rahmen von PISA 2000. Wiesbaden: VS, Verlag für Sozialwissenschaften, 2006, p. 61-94.

YOUNG, J. Soziale Exklusion. In: Widersprüche, v. 58, n. 98, 2005, p. 7-11.

ZINNECKER, J. Jugendkultur 1940-1985.Opladen: Verlag Leske + Budrich, 1985. 